\title{
A Multicriteria Analysis of Photovoltaic Systems: Energetic, Environmental, and Economic Assessments
}

\author{
Federica Cucchiella and Idiano D'Adamo \\ Department of Industrial and Information Engineering and Economics, University of L'Aquila, Via G. Gronchi 18, 67100 L'Aquila, Italy
}

Correspondence should be addressed to Federica Cucchiella; federica.cucchiella@univaq.it

Received 11 December 2014; Revised 11 February 2015; Accepted 15 February 2015

Academic Editor: Mahmoud M. El-Nahass

Copyright (c) 2015 F. Cucchiella and I. D’Adamo. This is an open access article distributed under the Creative Commons Attribution License, which permits unrestricted use, distribution, and reproduction in any medium, provided the original work is properly cited.

\begin{abstract}
The development of photovoltaic (PV) energy has led to rising efficiencies, better reliability, and falling prices. A multicriteria analysis (MCA) of PV systems is proposed in this paper in order to evaluate the sustainability of alternative projects. The investigations are presented using multiple indicators: Energy Payback Time (EPBT), Energy Return on Investment (EROI), Greenhouse Gas per kilowatt-hour (GHG/kWh), Greenhouse Gas Payback Time (GPBT), Greenhouse Gas Return on Investment (GROI), Net Present Value (NPV), Discounted Payback Time (DPBT), and Discounted Aggregate Cost Benefit $\left(D(B / C)_{A}\right)$. PV energy is a relevant player in global electricity market and can have a key-role in sustainable growth.
\end{abstract}

\section{Introduction}

The integration of the economic, energetic, and environmental goals is a phenomenon in rapid growth, particularly for those sectors and activities where the environmental impact is relevant $[1,2]$. The energy sector plays an important role for national development and several studies have defined as the fossil fuel contributes to worldwide environmental pollution with an expected increase in average temperature over the long term $[3,4]$.

Finding clean energy sources is one of the biggest challenges for humanity in the 21st century and renewable energy systems (RESs) are considered as a solution for mitigating climate change $[5,6]$. PV power is currently one of the fastest growing power-generation technologies at the worldwide level, mostly driven by technological improvements that reduced costs and government policies supportive of renewable energy $[7,8]$. PV energy is a sustainable choice for the future and there were $37 \mathrm{GW}$ of PV systems installed in 2013 at the worldwide level, which represents an increase of $36 \%$ with respect to previous year [9].

MCA is applied mainly to sustainability appraisals and its role is important in decision problems in the context of energy planning $[10,11]$. MCA improves the quality of decisions involving multiple indicators (criteria) by making choices more appropriate and efficient $[12,13]$.

A PV project investment can be evaluated through multiple indexes. This paper aims to develop a methodology based on MCA that allows comparing different PV facilities from environmental, economic, and energetic perspective. The indicators used are EPBT, EROI, GHG/kWh, GPBT, GROI, NPV, DPBT, and $D(B / C)_{A}$. This model provides a ranking of alternative projects

(i) that use different technologies (i.e., concentrated solar power, thin film, and crystalline);

(ii) that are located in different geographic areas (i.e., territories in same country or among several countries);

(iii) that may be also compared with other energy sources (fossil fuels and renewable).

The uncertainty may depend on two factors: (i) the volatility of input data and (ii) the percentual weight of the indicators. The optimal solution changes according to the preferences of the decision maker. The aim is to maximize the value of sustainability. A case study is proposed in this paper, in which monocrystalline silicon (c-Si) PV facilities that are located in 
all Italian regions are compared and a survey that involved experts in energy sector is conducted.

\section{Literature Review}

Multicriteria decision analysis (MCDA, also known as multicriteria decision-making (MCDM)) and cost-benefit analysis (CBA) are used extensively in power generation sector [14]. MCDM methods, unlike CBA that are unidimensional, allow analysing several factors as financial performance in addition to technical, social, or even esthetic dimensions [15]. MCDA is the application of MCA in decision-making problems and these methods have been applied to several different types of energy problems. Furthermore the multidimensional approaches, which characterize MCA, permit analysing companies' performance and defining improvements in their decision-making process [16].

MCDA is gaining popularity in sustainable energy management, which is characterized by multiple decision makers and multiple criteria. An interesting paper has proposed an overview of MCDM methods: weighted sum method (WSM), weighted product method (WPM), analytical hierarchy process (AHP), preference ranking organization method for enrichment evaluation (PROMETHEE), the elimination and choice translating reality (ELECTRE), the technique for order preference by similarity to ideal solutions (TOPSIS), compromise programming (CP), and multiattribute utility theory (MAUT) [17].

MCDM can require a simple approach or a sophisticated method based on mathematical programming and this depends on several aspects: (i) features of projects, (ii) typologies of decision makers, and (iii) amount of information required $[13,18]$. Input data, criteria selection, criteria weighting, evaluation, and final aggregation are uncertain and the purpose of MCDM methods is to correlate efficiently various factors in order to come to a final decision as to the advantages or disadvantages of a project $[19,20]$. MCDA is a form of integrated sustainability evaluation and in literature several indexes are presented:

(i) the multicriteria evaluation of the priority rating among the options of energy systems can be defined by a General Index of Sustainability. The indicators considered are five: efficiency, investment cost, electricity cost, area of energy facilities, and $\mathrm{CO}_{2}$ emission [21];

(ii) the evaluation of the country's market regarding renewable energy technologies is defined by Renewable Energy Market Competence Index. It includes eighteen quantitative indicators, which are divided into macro-areas: finance, environment, policy, economy, technology, and energy [22];

(iii) a literature review on sustainable energy decisionmaking defines that efficiency, investment cost, $\mathrm{CO}_{2}$ emission, and job creation are the most common criteria in the technical, economic, environmental, and social attributes, respectively [23].
The following section describes the methodology used that is derived by MCDA concepts.

\section{Methodology}

MCDM method allows analysing several aspects of PV performance and it is composed of several phases:

(1) definition of the projects (Section 3.1);

(2) definition of judgement criteria (Sections 3.2-3.5);

(3) assignment of weight to each criterion (Section 3.6);

(4) aggregation of judgements (Section 4).

3.1. Case Study. This paper proposes a methodology that considers energetic, economic, and environmental performance of PV facilities and defines the optimal solution among alternative projects. The environmental protection and economic profit can coexist in an investment in residential photovoltaic power generation facilities in Italy [24]. Thus, all Italian regions are chosen as case study and consequently the number of alternative projects is equal to twenty. In fact, the great difficulty of this methodology is the evaluation of all indicators [25] and the sustainable management framework defined in this study has drawn on previous analyses [26, 27].

The aim of MCA is to define a value of sustainability $(S)$ for each alternative project $(J)$. It is calculated by the product of $I$ (row vector that represents the list of judgement criteria) with $W$ (column vector that represents the weight to each criteria):

$$
S_{J}=I_{J} * W_{J} \quad \text { with } J=\text { project. }
$$

The following step is the definition of judgement criteria for evaluating twenty alternative projects.

3.2. Indicators. The use of appropriate indicators for determining the sustainability of an energy system is a critical phase of decision making. In this paper we have proposed the principal metrics used by researchers and experts of energy sector [25-27]:

(i) EPBT is the time in which the energy input during the system life cycle is compensated by electricity generated by the system;

(ii) EROI measures how much energy is gained after accounting for the energy required to produce a unit of the energy in question;

(iii) GHG/kWh is the total amount of $\mathrm{CO}_{2}$ equivalent emitted over the full life cycle of a system divided the total kWh output by the system;

(iv) GPBT is the time in which the GHG emissions during the system life cycle are compensated by GHG saved by alternative installation;

(v) GROI indicates the GHG emissions saved for every unit of GHG emitted; 
(vi) NPV is the sum that results when the discounted values of the expected costs of an investment are deducted from the discounted value of the expected revenues;

(vii) DPBT represents the number of required years so that the cumulative discounted cash flows equate the initial investment;

(viii) $D(B / C)_{A}$ is the ratio between discounted economic benefits and costs:

$$
\begin{gathered}
\mathrm{EPBT}=\frac{E_{\mathrm{IN}}}{E_{\mathrm{OUT}}}, \\
\mathrm{EROI}=\frac{E_{\mathrm{OUT}, \mathrm{GLB}}}{E_{\mathrm{IN}}}, \\
\frac{\mathrm{GHG}}{\mathrm{kWh}}=\frac{\mathrm{GHG}_{\mathrm{EM}}}{E_{\mathrm{OUT}, \mathrm{GLB}}}, \\
\mathrm{GPBT}=\frac{\mathrm{GHG}_{\mathrm{EM}}}{\mathrm{GHG}_{\mathrm{SV}}}, \\
\mathrm{GROI}=\frac{\mathrm{GHG}_{\mathrm{SV}, \mathrm{GLB}}}{\mathrm{GHG}_{\mathrm{EM}}}, \\
\sum_{t=0}^{N} \frac{C_{t}}{(1+r)^{t}}=\sum_{t=0}^{N} \frac{I_{t}-O_{t}}{(1+r)^{t}}, \\
\sum_{t=0}^{\mathrm{DPBT}} \frac{C_{t}}{(1+r)^{t}}=0, \\
=\frac{\sum_{t=0}^{N}\left(\left(I_{t}+\mathrm{SCC}_{t}\right) /(1+r)^{t}\right)}{\sum_{t=0}^{N}\left(O_{t} /(1+r)^{t}\right)},
\end{gathered}
$$

where $E_{\mathrm{IN}}$ is the embodied energy of the system and BOS $(\mathrm{kWh}) ; E_{\text {OUT }}$ is the annual energy output of the system $(\mathrm{kWh} / \mathrm{y}) ; E_{\mathrm{OUT}}$ GLB is the total energy output of the system during all of the life cycle (kWh); $\mathrm{GHG}_{\mathrm{EM}}$ (GHG emitted) is the emissions associated with the life cycle PV electricity production ( $\left.\mathrm{kgCO}_{2} \mathrm{eq}\right) ; \mathrm{GHG}_{\mathrm{SV}}$ (GHG saved) is the annual emissions saved by the power generated by the renewable system and not by fossil fuels $\left(\mathrm{kgCO}_{2} \mathrm{eq} / \mathrm{y}\right) ; \mathrm{GHG}_{\mathrm{SV}, \mathrm{GLB}}$ is the total emissions saved by installing new electricity capacity $\left(\mathrm{kgCO}_{2} \mathrm{eq}\right) ; t$ is the single period (year); $N$ is the lifetime $(20 \mathrm{y}) ; C_{t}$ is the discounted cash flows $(€ / \mathrm{y}) ; I_{t}$ is the annual discounted cash inflows $(€ / y) ; O_{t}$ is the annual discounted cash outflows $(€ / y) ; r$ is the opportunity cost of capital (5\%); $\mathrm{SCC}_{t}$ is the annual social cost of carbon ( $\left.€ / \mathrm{y}\right)$ [27].

Each indicator provides a specific output and the choice of the best metric depends on decision maker's utility function. It is possible to divide these indicators in function of their nature: economic (NPV, DPBT, and $\left.D(B / C)_{A}\right)$, energetic (EPBT, EROI), and environmental (GHG/kWh, GPBT, and GROI). Furthermore three of these metrics (DPBT, EPBT, and GPBT) do not consider all life cycle of PV system. Once all judgement criteria are identified, useful approach is represented by the combination of these results. MCA aims to this goal. It is possible to define row vector $I$ that is composed by eight columns (equal to number of indicators):

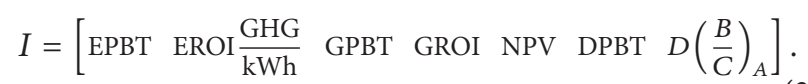

The following subsections propose technical, energetic, environmental, and economic inputs in order to quantify the several indicators.

3.3. Technical and Energetic Input. The choice of design process of a PV system depends on several variables. If generally the amount of electricity generated by system $\left(E_{\mathrm{OUT}}\right)$ is defined according to the consumer demand for energy $\left(Q_{E L}\right)$, in this paper the $1 \mathrm{~kW}$ plant is analysed (normalised size):

$$
\begin{gathered}
E_{\mathrm{OUT}, t}=t_{r} * K_{f} * E_{f} * E_{\mathrm{bos}} * A_{\text {cell }} * P_{f} * \eta_{f}, \\
E_{\mathrm{OUT}, t+1}=E_{\mathrm{OUT}, t} *\left(1-d E_{f}\right) \quad \text { with } t=1, \ldots, N, \\
Q_{\mathrm{EL}, t+1}=Q_{\mathrm{EL}, t} *\left(1+Q_{\% \mathrm{EL}}\right), \\
E_{\mathrm{OUT}, \mathrm{GLB}}=\sum_{t=1}^{N} E_{\mathrm{OUT}, t},
\end{gathered}
$$

where $E_{\text {OUT, } t}$ is the annual energy output of the system $(\mathrm{kWh} / \mathrm{y}) ; t_{r}$ is the average annual insolation (1275$\left.1633 \mathrm{kWh} / \mathrm{m}^{2} * \mathrm{y}\right) ; K_{f}$ is the optimum angle of tilt (1.13); $E_{f}$ is the embodied energy of the PV module fabrication (16\%); $E_{\text {bos }}$ is the embodied energy of BOS (85\%); $A_{\text {cell }}$ is the active surface $\left(7 \mathrm{~m}^{2} / \mathrm{kWp}\right) ; P_{f}$ is the nominal power of a PV module $(0.20 \mathrm{kWp}) ; \eta_{f}$ is the number of PV modules to be installed (it is chosen in function of size, in this case being equal to 5); $\mathrm{dE}_{f}$ is the annual decrease efficiency of system $\left(\mathrm{dE}_{f}\right) 0.7 \% ; \mathrm{Q}_{\mathrm{EL}, t}$ is the annual electric energy required by consumers (kWh); $Q_{E L, 1}$ is the electric energy required by consumers in 1st year $(1000 \mathrm{kWh}) ; Q_{\% \mathrm{EL}}$ is the annual electricity energy increase required by consumers $(1 \%)[27,28]$.

The Life Cycle Assessment permits evaluating the amount of energy used in the manufacturing, transport, construction, operation, decommissioning, and other life cycle stages of the PV facility:

$$
\begin{aligned}
E_{\mathrm{IN} / A} & =\left(E_{P}+E_{S}+E_{F}+E_{\mathrm{BOS}}+E_{T}+E_{D}\right) * C, \\
E_{\mathrm{IN}} & =E_{\mathrm{IN} / A} * A_{\text {cell }}
\end{aligned}
$$

where $E_{\mathrm{IN} / A}$ is the embodied energy per unit effective area $\left(\mathrm{kWh} / \mathrm{m}^{2}\right) ; C$ is conversion factor of electricity in primary energy $(0.40 \mathrm{kWhel} / \mathrm{kWht}) ; E_{P}$ is the embodied energy of silicon purification and processing $\left(666 \mathrm{kWht} / \mathrm{m}^{2}\right) ; E_{S}$ is the embodied energy of silicon ingot slicing $\left(120 \mathrm{kWht} / \mathrm{m}^{2}\right)$; $E_{F}$ is the embodied energy of PV module fabrication $\left(190 \mathrm{kWht} / \mathrm{m}^{2}\right) ; E_{\mathrm{BOS}}$ is the embodied energy of the BOS $\left(443 \mathrm{kWht} / \mathrm{m}^{2}\right) ; E_{T}$ is the energy for transport PV modules from factory to installation site $\left(40 \mathrm{kWht} / \mathrm{m}^{2}\right) ; E_{D}$ is the energy requirements for decommissioning and disposal or other end-of-life energy (25 kWht/m²) [26]. 
3.4. Environmental Input. The GHG emissions normally occur during all of the phases of a life cycle of a PV system. GHG covers six categories of greenhouse gases $\left(\mathrm{CO}_{2}, \mathrm{CH}_{4}\right.$, $\mathrm{N}_{2} \mathrm{O}, \mathrm{HFC}, \mathrm{PFC}$, and $\mathrm{SF}_{6}$ ) and is estimated using the $\mathrm{CO}_{2}$ equivalent $\left(\mathrm{CO}_{2} \mathrm{eq}\right)$, a metric used to compare the emissions from various greenhouse gases based upon their global warming potential:

$$
\begin{gathered}
\mathrm{GHG}_{\mathrm{EM}}=\mathrm{GHG}_{M}+\mathrm{GHG}_{\mathrm{OM}}+\mathrm{GHG}_{T}+\mathrm{GHG}_{D}, \\
\mathrm{GHG}_{\mathrm{SV}, t}=E_{\mathrm{OUT}, t} * F_{\mathrm{MIXE}} \\
\mathrm{GHG}_{\mathrm{SV}, \mathrm{GLB}}=\sum_{t=1}^{N} \mathrm{GHG}_{\mathrm{SV}, t}
\end{gathered}
$$

where $\mathrm{GHG}_{M}$ (GHG manufacturing) is emissions related to the manufacturing phase of a $\mathrm{PV}$ system (2186 $\mathrm{kgCO}_{2} \mathrm{eq} / \mathrm{kWp}$ ); $\mathrm{GHG}_{\mathrm{OM}}$ (GHG operations maintenance) is emissions during the operations of maintenance (82 $\mathrm{kgCO}_{2} \mathrm{eq} / \mathrm{kWp}$ ); $\mathrm{GHG}_{T}$ (GHG transport) is the emissions related to the transport of the $\mathrm{PV}$ modules from the factory to the installation site $\left(21 \mathrm{kgCO}_{2} \mathrm{eq} / \mathrm{kWp}\right) ; \mathrm{GHG}_{D}$ (GHG disposal) is the emissions for the decommissioning and disposal of the cells at the end of their lifetime $\left(44 \mathrm{kgCO}{ }_{2} \mathrm{eq} / \mathrm{kWp}\right) ; \mathrm{GHG}_{\mathrm{SV}, t}$ is the annual emissions saved by the power generated by the renewable system and not by fossil fuels $\left(\mathrm{kgCO}_{2} \mathrm{eq} / \mathrm{y}\right) ; F_{\mathrm{MIXE}}$ is the emission factor, based on the Italian electricity production mix $\left(0.53 \mathrm{kgCO}_{2}\right.$ eq/kWh) [26].

3.5. Economic Input. The role of self-consumption is strategic and supports the profitability of PV facilities in a mature market characterised by the absence of public policy incentives (e.g., Italy) [9]. In this paper the percentage of energy-self consumption is equal to $50 \%$, because in $1 \mathrm{~kW}$ plant there is a probability of harmonization between energy demand and energy required greater than typical residential plant (30\%). The Discounted Cash Flow (DCF) is the methodology used and the entire investment cost is covered by third party funds:

$$
\begin{gathered}
I_{t}=\mathrm{SC}_{\mathrm{el}, t}+\mathrm{SP}_{\mathrm{el}, t}+\mathrm{TaxD}_{t}, \\
0_{t}=C_{\mathrm{lcs}, t}+C_{\mathrm{lis}, t}+C_{m, t}+C_{\mathrm{ass}, t}+C_{\mathrm{tax}, t}, \\
\mathrm{SC}_{\mathrm{el}, t}=x_{t}^{c} * p_{t}^{c} \quad \forall t=1, \ldots, N, \\
\mathrm{SP}_{\mathrm{el}, t}=x_{t}^{s} * p_{t}^{s} \quad \forall t=1, \ldots, N, \\
x_{t}^{c}=\omega_{\mathrm{self}, c} * E_{\mathrm{OUT}, t} ; \quad x_{t}^{s}=\omega_{\mathrm{sold}} * E_{\mathrm{OUT}, t} \text { with } \\
\omega_{\mathrm{self}, c}+\omega_{\mathrm{sold}}=1, \\
\operatorname{TaxD}_{t}=\frac{C_{\mathrm{inv}}}{N_{\mathrm{TaxD}}} * \operatorname{TaxD}{ }_{\mathrm{unit}} \quad \forall t=1, \ldots, N_{\mathrm{TaxD}}, \\
p_{t+1}^{c}=p_{t}^{c} *\left(1+\inf _{\mathrm{el}}\right),
\end{gathered}
$$

$$
\begin{gathered}
p_{t+1}^{s}=p_{t}^{s} *\left(1+\mathrm{inf}_{\mathrm{el}}\right), \\
C_{\mathrm{inv}}=C_{\mathrm{inv}, \mathrm{unit}} *(1+\mathrm{VAT}) * P_{f} * \eta_{f}, \\
C_{\mathrm{lcs}, t}=\frac{C_{\mathrm{inv}}}{N_{\mathrm{debt}}} \quad \forall t=0, \ldots, N_{\mathrm{debt}}-1, \\
C_{\mathrm{lis}, t}=\left(C_{\mathrm{inv}}-C_{\mathrm{lcs}, t}\right) * r_{d} \quad \forall t=0, \ldots, N_{\mathrm{debt}}-1, \\
C_{m, t}=P_{\mathrm{Cm}} * C_{\mathrm{inv}} *(1+\mathrm{inf}) \quad \forall t=1, \ldots, N, \\
C_{\mathrm{ass}, t}=P_{\mathrm{Cass}} * C_{\mathrm{inv}} *(1+\mathrm{inf}) \quad \forall t=1, \ldots, N, \\
C_{\mathrm{tax}, t}=\mathrm{SP}_{\mathrm{el}, t} * P_{\mathrm{Ctax}} \quad \forall t=1, \ldots, N, \\
\mathrm{SCC}_{t}=\mathrm{SCC}_{\mathrm{unit}, t} * \mathrm{GHG}_{\mathrm{SV}, t} \quad \forall t=1, \ldots, N,
\end{gathered}
$$

where $\mathrm{SC}_{\mathrm{el}, t}$ is the annual saving energy internal consumption $(€ / \mathrm{y}) ; \mathrm{SC}_{\mathrm{el}, t}$ is the sale of energy not for internal consumption $(€ / \mathrm{y})$; $\operatorname{TaxD}_{t}$ is the annual fiscal deduction $(€ / \mathrm{y}) ; C_{\mathrm{lcs}, t}$ is the annual loan capital share cost $(€ / \mathrm{y}) ; C_{\text {lis }, t}$ is the annual loan interest share cost $(€ / \mathrm{y}) ; C_{m, t}$ is the annual maintenance cost $(€ / y) ; C_{\text {ass }, t}$ is the annual assurance cost $(€ / y) ; C_{\text {tax }, t}$ is the annual taxes cost $(€ / y) ; x_{t}^{c}$ is the amount of self-consumed electricity $(\mathrm{kWh}) ; p_{t}^{c}$ is the annual electricity purchase price $(0.19 € / \mathrm{kWh}) ; x_{t}^{s}$ is the amount of electricity sold to the grid $(\mathrm{kWh}) ; p_{t}^{s}$ is the annual electricity sales price $(0.109 € / \mathrm{kWh})$; $\omega_{\text {self,c }}$ is the percentage of energy self-consumption (50\%); $\omega_{\text {sold }}$ is the percentage of the produced energy sold to the grid (50\%); $C_{\text {inv }}$ is the total investment cost $(€) ; N_{\text {TaxD }}$ is the period of tax deduction $(10 \mathrm{y})$; $\mathrm{TaxD}_{\text {unit }}$ is the tax deduction unitary (50\%); $\inf _{\mathrm{el}}$ is the rate of energy inflation (1.9\%); $C_{\text {inv,unit }}$ is the unitary investment cost $(2000 € / \mathrm{kW})$; VAT is the value added tax (10\%); $N_{\text {debt }}$ is the period of loan $(15 \mathrm{y})$; $r_{d}$ is the interest rate on loan $(3 \%) ; P_{\mathrm{Cm}}$ is the percentage of maintenance cost (1\%); inf is the rate of inflation $(1.5 \%)$; $P_{\text {Cass }}$ is the percentage of assurance cost $(0.4 \%) ; P_{\text {Ctax }}$ is the percentage of taxes cost $(27.5 \%)$; $\mathrm{SCC}_{\text {unit, } t}$ is the annual unitary social cost of carbon $\left(6 € / \mathrm{tCO}_{2} \mathrm{eq}\right)[9,29]$.

The following subsection proposes the third phase of methodology, represented by assignment of weight to each criterion.

3.6. Analytical Hierarchy Process. The AHP is a theory and process of measurement through pairwise comparisons based upon the judgments of experts to derive the priority scales $[13,30]$. The accuracy of the analysis depends on the user's knowledge in the area [31, 32], so the authors used a survey that involved twelve among senior managers, policy makers, and researchers with extensive experience in energy decision-making. We employed the one to nine judgment scale recommended in the literature [33]. The value of 1 indicates equally preferred, 2 equally to moderately preferred, 3 moderately preferred, 4 moderately to strongly preferred, 5 strongly preferred, 6 strongly to very strongly preferred, 7 very strongly preferred, 8 very to extremely strongly preferred, 7 and 9 extremely preferred.

These pair-wise comparisons were performed for all criteria to be considered, until the matrix was completed. Sixty-four values assigned by each decision maker were 
been aggregated and consequently their average values are calculated considering twelve respondents. There are several methods for calculating the weight vector $(W)$ and we used the approach of normalizing used by [34]. $W$ is a column vector, composed by eight rows (equal to number of criteria) as follows:

$$
W=\left[\begin{array}{c}
w_{\mathrm{EPBT}} \\
w_{\mathrm{EROI}} \\
w_{\mathrm{GHG} / \mathrm{kWh}} \\
w_{\mathrm{GPBT}} \\
w_{\mathrm{GROI}} \\
w_{\mathrm{NPV}} \\
w_{\mathrm{DPBT}} \\
w_{D(B / C) A}
\end{array}\right]
$$$$
=\frac{1}{8} *\left[\begin{array}{llllllll}
0.03 & 0.02 & 0.02 & 0.01 & 0.04 & 0.02 & 0.01 & 0.01 \\
0.17 & 0.09 & 0.03 & 0.15 & 0.09 & 0.04 & 0.22 & 0.15 \\
0.17 & 0.36 & 0.12 & 0.18 & 0.04 & 0.06 & 0.26 & 0.22 \\
0.09 & 0.02 & 0.02 & 0.03 & 0.03 & 0.02 & 0.01 & 0.01 \\
0.11 & 0.18 & 0.49 & 0.18 & 0.18 & 0.04 & 0.22 & 0.22 \\
0.20 & 0.27 & 0.25 & 0.21 & 0.53 & 0.11 & 0.01 & 0.29 \\
0.09 & 0.02 & 0.02 & 0.09 & 0.04 & 0.69 & 0.04 & 0.01 \\
0.14 & 0.05 & 0.04 & 0.15 & 0.06 & 0.03 & 0.22 & 0.07
\end{array}\right]
$$

$$
=\left[\begin{array}{l}
0.02 \\
0.12 \\
0.18 \\
0.03 \\
0.20 \\
0.23 \\
0.12 \\
0.10
\end{array}\right]
$$

It widely believed that it is useful to have a sustainable index that summarizes all different perspectives. A green project must be also profitable. Economic indicators have a weight (45\%) greater than environmental (41\%) and energetic (14\%) ones. In particular the survey respondents have defined NPV as criterion that presents the best relevance (equal to $23 \%$ ) to reach the sustainable goal. In electricity market without subsidies, the profitability depends on self-consumption share. In this direction, the improvement of consumption behaviours can significantly contribute to make a country more sustainable.

\section{Results}

Life cycle analysis considers all aspects of entire life cycle of a PV system and represents an important tool for the decision maker to establish the investment strategy. PV systems play an important role in sustainability of energy systems and the use of appropriate indicators is a critical phase of decisionmaking. Furthermore the use of quantitative methodologies is a useful tool for the correct choice of energy policies and the methodology proposed in this paper moves towards this goal.

MCA is a form of integrated sustainability evaluation that allows analysing the projects under several points of view. The aggregation of judgements is proposed in this section. We analyze economic, energetic, and environmental aspects. Indicator vector is calculated in Table 1 for each Italian region in function of input defined in Section 3. These values from one side permit defining the sustainability of each PV system and by other side can be not used directly in MCA. In fact, a comparison among several criteria required that the indicators vector must be normalized (Table 2).

The components of this row vector, which correspond to single indicators, can be equal to 1 or 0 in correspondence, respectively, of the maximum or minimum value. For example, if EROI is equal to 7.9 for Sicilia and 6.2 for Valle d'Aosta (Table 1) consequently the second component of vector $I$ is equal to 1 for Sicilia and 0 for Valle d'Aosta (Table 2). When an intermediate value is considered, for example, EROI being equal to 6.6 in Lombardia, the normalized value is calculated as follows: $(6.6-6.2) /(7.9-6.2) \approx 0.2$.

A normalized sustainability value is calculated for each Italian region $(J)$ creating a ranking of these PV systems (Table 3$)$. These values are obtained by the product between Table $2\left(I_{J}\right)$ and $(8)\left(W_{J}\right)$ and following the value of sustainability $\left(S_{J}\right)$ of Puglia is proposed:

$$
\begin{aligned}
S_{\text {Puglia }} & =I_{\text {Puglia }} * W_{\text {Puglia }} \\
& =\left[\begin{array}{llllllll}
0.8 & 0.7 & 0.8 & 0.7 & 0.7 & 0.6 & 1.0 & 0.6
\end{array}\right] *\left[\begin{array}{l}
0.02 \\
0.12 \\
0.18 \\
0.03 \\
0.20 \\
0.23 \\
0.12 \\
0.10
\end{array}\right]
\end{aligned}
$$

$$
=0.72 \text {. }
$$

The results highlight that

(i) all EPBT, GPBT, and DPBT are estimated to be less than useful lifetime of the systems. The EPBT of the PV systems analysed is estimated to vary from 2.4 to 3.0 years, GPBT from 2.5 to 3.2 years, and DPBT from 4 to 6 years; 
TABLE 1: Economic, energetic, and environmental indicators.

\begin{tabular}{|c|c|c|c|c|c|c|c|c|}
\hline Regions & EPBT & EROI & GHG/kWh & GPBT & GROI & NPV & DPBT & $D(B / C)_{A}$ \\
\hline Sicilia & 2.4 & 7.9 & 71 & 2.5 & 7.5 & 775 & 4 & 1.29 \\
\hline Sardegna & 2.5 & 7.6 & 74 & 2.6 & 7.2 & 681 & 4 & 1.25 \\
\hline Calabria & 2.5 & 7.6 & 74 & 2.6 & 7.2 & 679 & 4 & 1.25 \\
\hline Puglia & 2.5 & 7.4 & 75 & 2.7 & 7.0 & 645 & 4 & 1.24 \\
\hline Basilicata & 2.5 & 7.4 & 76 & 2.7 & 6.9 & 628 & 5 & 1.24 \\
\hline Campania & 2.5 & 7.3 & 76 & 2.7 & 6.9 & 627 & 5 & 1.24 \\
\hline Lazio & 2.6 & 7.2 & 77 & 2.7 & 6.8 & 606 & 5 & 1.23 \\
\hline Molise & 2.6 & 7.2 & 78 & 2.8 & 6.8 & 599 & 5 & 1.23 \\
\hline Abruzzo & 2.6 & 7.1 & 79 & 2.8 & 6.7 & 576 & 5 & 1.22 \\
\hline Umbria & 2.7 & 7.1 & 80 & 2.8 & 6.7 & 570 & 5 & 1.22 \\
\hline Marche & 2.7 & 7.0 & 80 & 2.8 & 6.6 & 558 & 5 & 1.22 \\
\hline Toscana & 2.7 & 7.0 & 80 & 2.8 & 6.6 & 554 & 5 & 1.21 \\
\hline Liguria & 2.7 & 6.9 & 82 & 2.9 & 6.5 & 536 & 5 & 1.21 \\
\hline Emilia R. & 2.7 & 6.9 & 82 & 2.9 & 6.5 & 533 & 5 & 1.21 \\
\hline Veneto & 2.8 & 6.7 & 84 & 3.0 & 6.3 & 496 & 5 & 1.19 \\
\hline Piemonte & 2.8 & 6.6 & 84 & 3.0 & 6.3 & 493 & 5 & 1.19 \\
\hline Lombardia & 2.8 & 6.6 & 85 & 3.0 & 6.2 & 485 & 6 & 1.19 \\
\hline Friuli V.G. & 2.9 & 6.4 & 88 & 3.1 & 6.1 & 421 & 6 & 1.17 \\
\hline Trentino A.A. & 3.0 & 6.3 & 89 & 3.2 & 5.9 & 421 & 6 & 1.17 \\
\hline Valle d'Aosta & 3.0 & 6.2 & 91 & 3.2 & 5.8 & 410 & 6 & 1.17 \\
\hline
\end{tabular}

EPBT (years); EROI (kWh/kWh); GHG/kWh (gCO $\left.\mathrm{g}_{2} \mathrm{eq} / \mathrm{kWh}\right) ; \mathrm{GPBT}$ (years); GROI (gCO $\left.\mathrm{geq}_{2} \mathrm{gCO}_{2} \mathrm{eq}\right) ; \mathrm{NPV}(€)$; DPBT (years); $D(B / C)_{A}(€ / €)$.

TABLE 2: Economic, energetic, and environmental normalized indicators.

\begin{tabular}{|c|c|c|c|c|c|c|c|c|}
\hline Regions & EPBT & EROI & GHG/kWh & GPBT & GROI & NPV & DPBT & $D(B / C)_{A}$ \\
\hline Sicilia & 1 & 1 & 1 & 1 & 1 & 1 & 1 & 1 \\
\hline Sardegna & 0.8 & 0.8 & 0.9 & 0.9 & 0.8 & 0.7 & 1 & 0.7 \\
\hline Calabria & 0.8 & 0.8 & 0.9 & 0.9 & 0.8 & 0.7 & 1 & 0.7 \\
\hline Puglia & 0.8 & 0.7 & 0.8 & 0.7 & 0.7 & 0.6 & 1 & 0.6 \\
\hline Basilicata & 0.8 & 0.7 & 0.8 & 0.7 & 0.6 & 0.6 & 0.5 & 0.6 \\
\hline Campania & 0.8 & 0.6 & 0.8 & 0.7 & 0.6 & 0.6 & 0.5 & 0.6 \\
\hline Lazio & 0.7 & 0.6 & 0.7 & 0.7 & 0.6 & 0.5 & 0.5 & 0.5 \\
\hline Molise & 0.7 & 0.6 & 0.7 & 0.6 & 0.6 & 0.5 & 0.5 & 0.5 \\
\hline Abruzzo & 0.7 & 0.5 & 0.6 & 0.6 & 0.5 & 0.5 & 0.5 & 0.4 \\
\hline Umbria & 0.5 & 0.5 & 0.6 & 0.6 & 0.5 & 0.4 & 0.5 & 0.4 \\
\hline Marche & 0.5 & 0.5 & 0.6 & 0.6 & 0.5 & 0.4 & 0.5 & 0.4 \\
\hline Toscana & 0.5 & 0.5 & 0.6 & 0.6 & 0.5 & 0.4 & 0.5 & 0.3 \\
\hline Liguria & 0.5 & 0.4 & 0.5 & 0.4 & 0.4 & 0.3 & 0.5 & 0.3 \\
\hline Emilia R. & 0.5 & 0.4 & 0.5 & 0.4 & 0.4 & 0.3 & 0.5 & 0.3 \\
\hline Veneto & 0.3 & 0.3 & 0.4 & 0.3 & 0.3 & 0.2 & 0.5 & 0.2 \\
\hline Piemonte & 0.3 & 0.2 & 0.4 & 0.3 & 0.3 & 0.2 & 0.5 & 0.2 \\
\hline Lombardia & 0.3 & 0.2 & 0.3 & 0.3 & 0.2 & 0.2 & 0 & 0.2 \\
\hline Friuli V.G. & 0.2 & 0.1 & 0.1 & 0.1 & 0.2 & 0 & 0 & 0 \\
\hline Trentino A.A. & 0 & 0.1 & 0.1 & 0 & 0.1 & 0 & 0 & 0 \\
\hline Valle d'Aosta & 0 & 0 & 0 & 0 & 0 & 0 & 0 & 0 \\
\hline
\end{tabular}

(ii) all EROI, GROI, and $D(B / C)_{A}$ ratios are greater than 1. The EROI of the PV systems analysed is estimated to vary from 6.2 to 7.9 , GROI from 5.8 to 7.5 , and $D(B / C)_{A}$ from 1.17 to 1.29 ;

(iii) all $\mathrm{GHG} / \mathrm{kWh}$ values are less than those related to fossil fuels. The minimum and maximum values are, respectively, $79 \mathrm{gCO}_{2} \mathrm{eq} / \mathrm{kWh}$ and $92 \mathrm{gCO}_{2} \mathrm{eq} / \mathrm{kWh}$; (iv) all NPV assume a value greater than 0 . The minimum and maximum values are, respectively, $410 €$ and $775 €$.

In this paper, a set of metrics has been analysed for the estimation of the economic, energetic, and environmental 
TABLE 3: Ranking of alternative projects.

\begin{tabular}{lc}
\hline Regions & Value of sustainability \\
\hline Sicilia & 1 \\
Sardegna & 0.81 \\
Calabria & 0.81 \\
Puglia & 0.72 \\
Basilicata & 0.64 \\
Campania & 0.63 \\
Lazio & 0.58 \\
Molise & 0.58 \\
Abruzzo & 0.52 \\
Umbria & 0.49 \\
Marche & 0.49 \\
Toscana & 0.48 \\
Liguria & 0.40 \\
Emilia R. & 0.40 \\
Veneto & 0.31 \\
Piemonte & 0.30 \\
Lombardia & 0.20 \\
Friuli V.G. & 0.08 \\
Trentino A.A. & 0.05 \\
Valle d'Aosta & 0 \\
\hline
\end{tabular}

impacts of the PV systems. PV investments are characterised by a dual source of convenience:

(i) enable environmental improvements;

(ii) represent profitable projects.

As can be expected, the higher levels of indicators are associated with locations with a higher level of insolation. There are clearly some interdependencies between critical variables (module efficiency, embodied energy of silicon purification and processing, embodied energy of the BOS, average annual insolation, emissions related to the manufacturing phase of a PV system, emission factor, investment cost, fiscal deduction, electricity purchase price, electricity sales price, and social cost of carbon) and indicators that are already examined in other papers [9, 26-28].

PV systems demonstrate that economic feasibility and environmental protection are not two conflicting concepts and their integration can reduce the degradation of ecosystems. All survey respondents define that a project can be not only green but also profitable and must be evaluated along all life cycle.

In this case study all indicators are convergent on the same result (Sicilia), but the normalized value of sustainability is high also in other southern areas (Sardegna, Calabria, and Puglia). This is related to the consideration that many of the critical variables have the same value for each region and consequently the annual solar irradiance has a higher criticality.

The methodology proposed in this paper could be used in order to compare not only photovoltaic systems but also renewable energy and/or fossil fuels in order to define the sustainable best solution. MCA and several indicators used are widely recognized in literature and consequently the variability may be limited to two aspects: (i) choice of values of input and (ii) choice of survey respondents. Furthermore also another pillar of sustainability (social perspective) could be analysed when the number of direct and indirect workers is critical and is not the same for several alternative projects.

\section{Conclusions}

The management as well as exploitation of PV energy is now recognised as central to sustainable development. It represents an important resource to become energy-independent. In this way, the amount of energy produced by fossil fuels is reduced and there is a reduction of pollutant emissions; furthermore relevant economic opportunities are generated by these investments. Another significant aspect is represented by the development of distributed generation systems, in which the role of PV energy will be crucial.

The use of appropriate indicators for determining the goodness of a PV system is a critical phase of decision making. Economic, environmental, and energetic indicators are used in order to evaluate the sustainability of a project and a survey, which involved senior managers, policy makers, and researcher, attributes a weight to each indicator. Two indicators are very important: profits of the project and GHG emissions saved for every unit of GHG emitted.

This paper has highlighted that average annual insolation is the most critical variable, when the comparison is among PV systems located in the same country. However the methodology proposed provides a broad application potential to support MCA method selection in the energy sector.

\section{Conflict of Interests}

The authors declare that there is no conflict of interests regarding the publication of this paper.

\section{References}

[1] S. Vinodh, K. Jayakrishna, V. Kumar, and R. Dutta, "Development of decision support system for sustainability evaluation: a case study," Clean Technologies and Environmental Policy, vol. 16, no. 1, pp. 163-174, 2014.

[2] T. T. Chow, G. N. Tiwari, and C. Menezo, "Hybrid solar: a review on photovoltaic and thermal power integration," International Journal of Photoenergy, vol. 2012, Article ID 307287, 17 pages, 2012.

[3] H. Kan, R. Chen, and S. Tong, "Ambient air pollution, climate change, and population health in China," Environment International, vol. 42, pp. 10-19, 2012.

[4] T.-T. Chow and J. Ji, "Environmental life-cycle analysis of hybrid solar photovoltaic/thermal systems for use in Hong Kong," International Journal of Photoenergy, vol. 2012, Article ID 101968, 9 pages, 2012.

[5] F. Cucchiella, I. D'Adamo, and M. Gastaldi, "Financial analysis for investment and policy decisions in the renewable energy sector," Clean Technologies and Environmental Policy, 2014. 
[6] C.-S. Jwo, S.-L. Chen, H. Chang, Y.-S. Su, and J.-S. Chen, "Solar energy and clean energy: trends and developments," International Journal of Photoenergy, vol. 2013, Article ID 749167, 2 pages, 2013.

[7] A. F. Abdul Kadir, T. Khatib, and W. Elmenreich, "Integrating photovoltaic systems in power system: power quality impacts and optimal planning challenges," International Journal of Photoenergy, vol. 2014, Article ID 321826, 7 pages, 2014.

[8] G. Ciulla, V. Lo Brano, V. Franzitta, and M. Trapanese, "Assessment of the operating temperature of crystalline PV modules based on real use conditions," International Journal of Photoenergy, vol. 2014, Article ID 718315, 11 pages, 2014.

[9] D. Chiaroni, V. Chiesa, L. Colasanti, F. Cucchiella, I. D’Adamo, and F. Frattini, "Evaluating solar energy profitability: a focus on the role of self-consumption," Energy Conversion and Management, vol. 88, pp. 317-331, 2014.

[10] M. Herva and E. Roca, "Review of combined approaches and multi-criteria analysis for corporate environmental evaluation," Journal of Cleaner Production, vol. 39, pp. 355-371, 2013.

[11] F. Cucchiella, I. D’Adamo, and M. Gastaldi, "Sustainable management of waste-to-energy facilities," Renewable and Sustainable Energy Reviews, vol. 33, pp. 719-728, 2014.

[12] G. Egilmez, S. Gumus, and M. Kucukvar, "Environmental sustainability benchmarking of the U.S. and Canada metropoles: an expert judgment-based multi-criteria decision making approach," Cities, vol. 42, part A, pp. 31-41, 2015.

[13] C.-R. Chen, C.-C. Huang, and H.-J. Tsuei, "A hybrid MCDM model for improving GIS-based solar farms site selection," International Journal of Photoenergy, vol. 2014, Article ID 925370, 9 pages, 2014.

[14] D. Diakoulaki and F. Karangelis, "Multi-criteria decision analysis and cost-benefit analysis of alternative scenarios for the power generation sector in Greece," Renewable and Sustainable Energy Reviews, vol. 11, no. 4, pp. 716-727, 2007.

[15] E. W. Stein, "A comprehensive multi-criteria model to rank electric energy production technologies," Renewable and Sustainable Energy Reviews, vol. 22, pp. 640-654, 2013.

[16] C. E. D. D. C. Infante, F. M. D. Mendonça, P. M. Purcidonio, and R. Valle, "Triple bottom line analysis of oil and gas industry with multicriteria decision making," Journal of Cleaner Production, vol. 52, pp. 289-300, 2013.

[17] S. D. Pohekar and M. Ramachandran, "Application of multicriteria decision making to sustainable energy planning-a review," Renewable and Sustainable Energy Reviews, vol. 8, no. 4, pp. 365-381, 2004.

[18] J. Xu, L. Kang, C. Zhong, and B. Cao, "Photovoltaic power system with MPPT functionality for a small-size electric vehicle," International Journal of Photoenergy, vol. 2014, Article ID 460390, 9 pages, 2014.

[19] K. D. Patlitzianas, G. K. Skylogiannis, and D. Papastefanakis, "Assessing the PV business opportunities in Greece," Energy Conversion and Management, vol. 75, pp. 651-657, 2013.

[20] Y.-L. Chen, C.-W. Yu, Z.-J. Chien, C.-H. Liu, and H.-H. Chiang, "On-road driver monitoring system based on a solarpowered in-vehicle embedded platform," International Journal of Photoenergy, vol. 2014, Article ID 309578, 12 pages, 2014.

[21] N. H. Afgan and M. G. Carvalho, "Multi-criteria assessment of new and renewable energy power plants," Energy, vol. 27, no. 8, pp. 739-755, 2002.

[22] H. Elrefaei, A. Bida, M. Hallouda, and M. Elsobky, "Renewable energy market competence index part 1: the methodology," Renewable Energy, vol. 53, pp. 400-412, 2013.
[23] J.-J. Wang, Y.-Y. Jing, C.-F. Zhang, and J.-H. Zhao, "Review on multi-criteria decision analysis aid in sustainable energy decision-making," Renewable and Sustainable Energy Reviews, vol. 13, no. 9, pp. 2263-2278, 2009.

[24] F. Cucchiella and I. D’Adamo, "Residential photovoltaic plant: environmental and economical implications from renewable support policies," Clean Technologies and Environmental Policy, 2015.

[25] F. Cucchiella and I. D’Adamo, "Issue on supply chain of renewable energy," Energy Conversion and Management, vol. 76, pp. 774-780, 2013.

[26] F. Cucchiella and I. Dadamo, "Estimation of the energetic and environmental impacts of a roof-mounted buildingintegrated photovoltaic systems," Renewable and Sustainable Energy Reviews, vol. 16, no. 7, pp. 5245-5259, 2012.

[27] F. Cucchiella, I. D’Adamo, and S. C. Lenny Koh, "Environmental and economic analysis of building integrated photovoltaic systems in Italian regions," Journal of Cleaner Production, 2013.

[28] F. Cucchiella and I. D’Adamo, "Feasibility study of developing photovoltaic power projects in Italy: an integrated approach," Renewable and Sustainable Energy Reviews, vol. 16, no. 3, pp. 1562-1576, 2012.

[29] F. Cucchiella, I. D’Adamo, M. Gastaldi, and S. C. L. Koh, "Renewable energy options for buildings: performance evaluations of integrated photovoltaic systems," Energy and Buildings, vol. 55, pp. 208-217, 2012.

[30] T. L. Saaty, The Analytic Hierarchy Process: Planning, Priority Setting, Resources Allocation, McGraw-Hill, New York, NY, USA, 1980.

[31] J.-T. Hsueh and C.-Y. Lin, "Constructing a network model to rank the optimal strategy for implementing the sorting process in reverse logistics: case study of photovoltaic industry," Clean Technologies and Environmental Policy, vol. 17, no. 1, pp. 155-174, 2015.

[32] J. Ren and B. K. Sovacool, "Prioritizing low-carbon energy sources to enhance China's energy security," Energy Conversion and Management, vol. 92, pp. 129-136, 2015.

[33] T. L. Saaty, "Decision making with the analytic hierarchy process," International Journal of Services Sciences, vol. 1, no. 1, pp. 83-98, 2008.

[34] R. Subramoniam, D. Huisingh, R. B. Chinnam, and S. Subramoniam, "Remanufacturing Decision-Making Framework (RDMF): research validation using the analytical hierarchical process," Journal of Cleaner Production, vol. 40, pp. 212-220, 2013. 

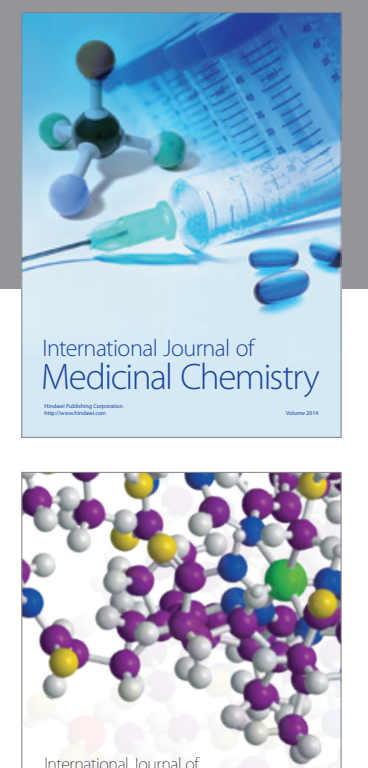

\section{Carbohydrate} Chemistry

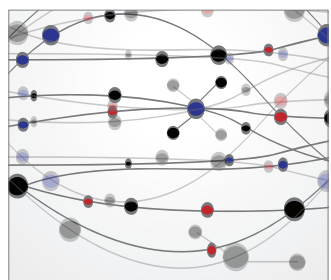

The Scientific World Journal
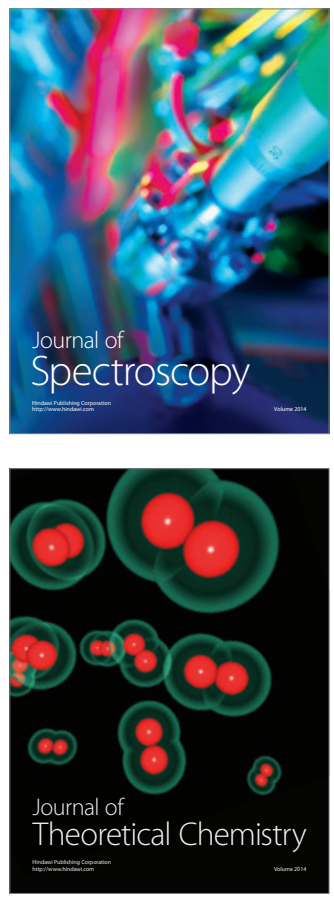
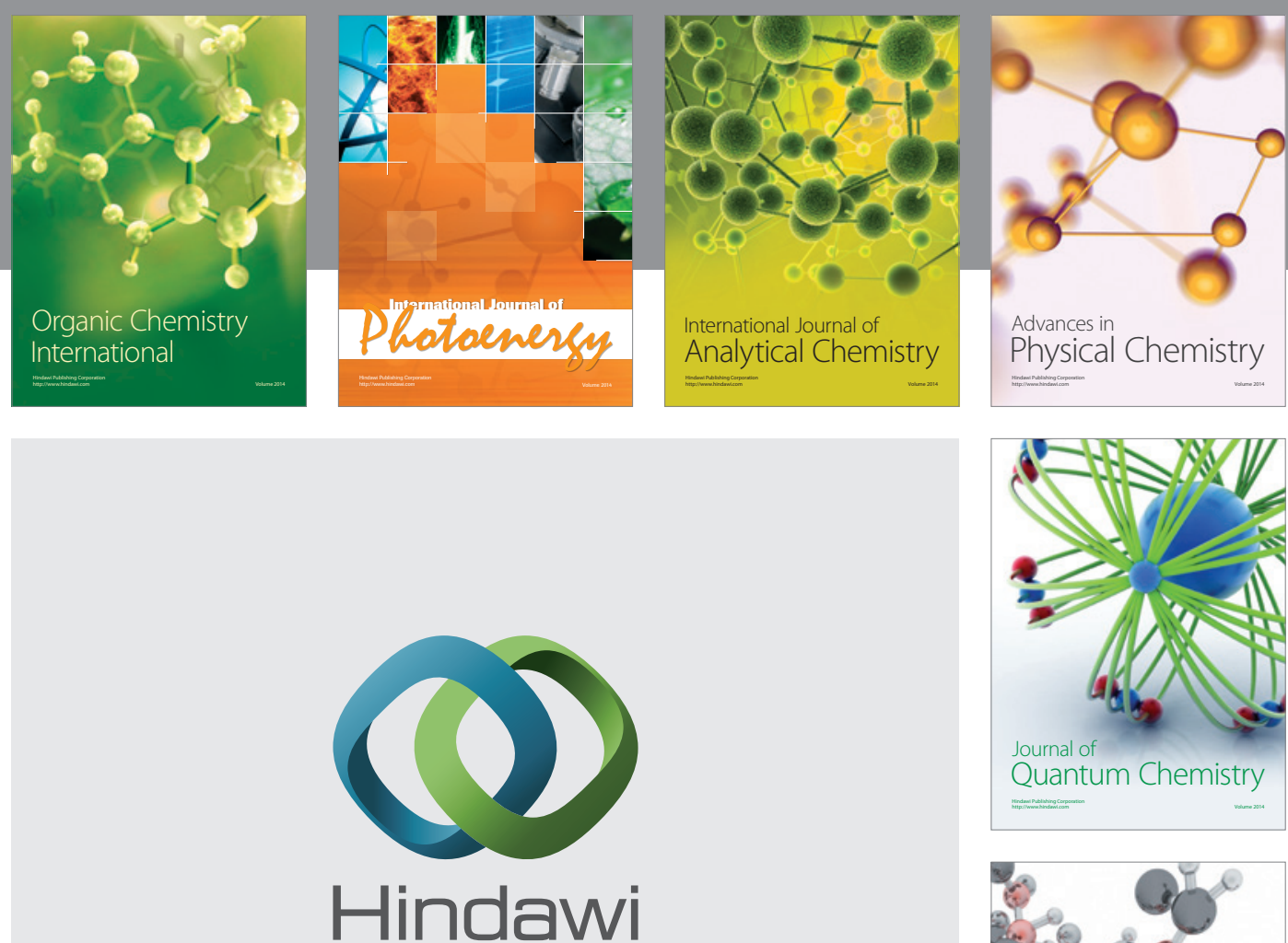

Submit your manuscripts at

http://www.hindawi.com

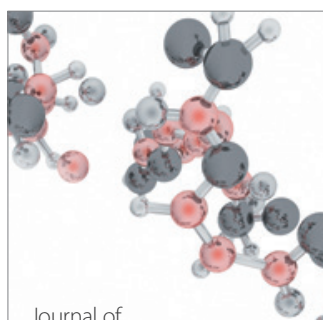

Analytical Methods

in Chemistry

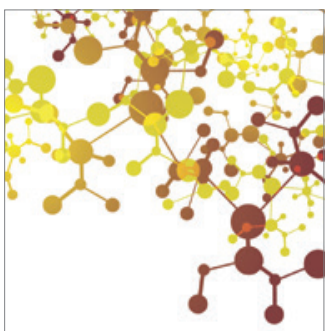

Journal of

Applied Chemistry

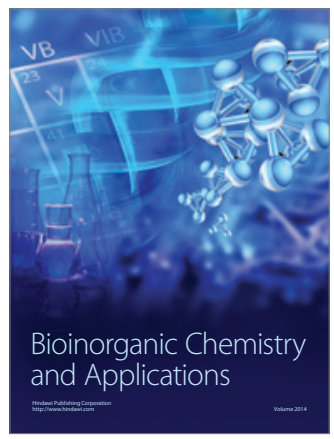

Inorganic Chemistry
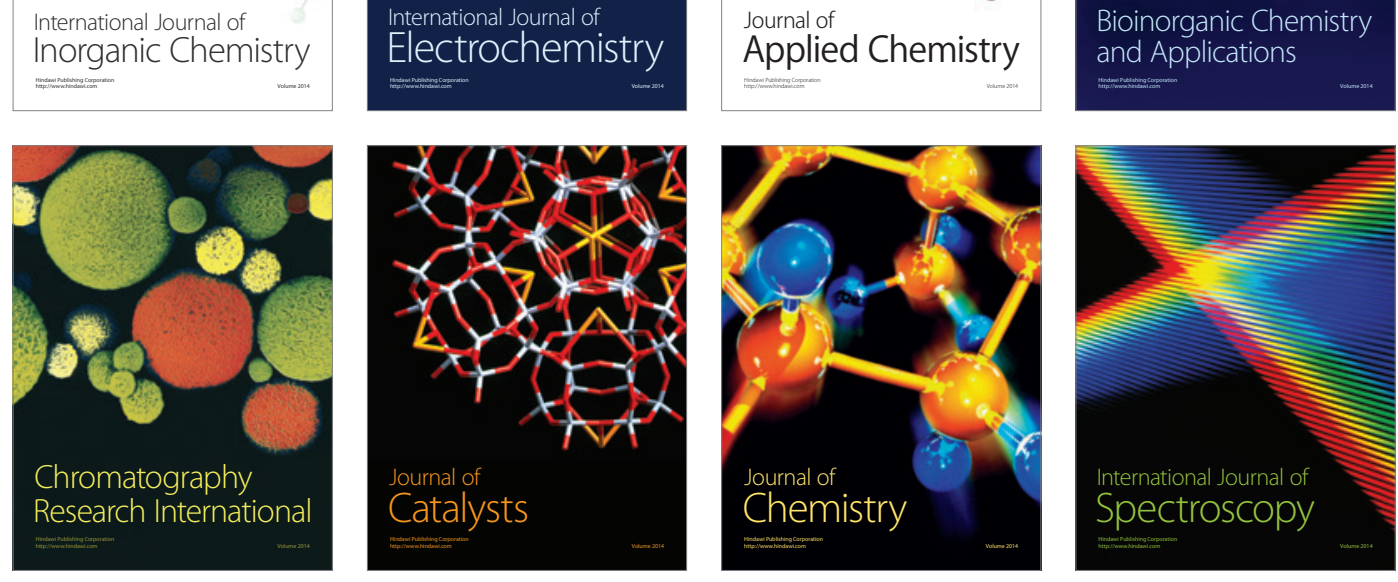